\title{
Coupling Transport of Water and Ions Through a Carbon Nanotube: The Role of Ionic Condition
}

\author{
Jiaye $\mathrm{Su}^{*}$, Decai Huang
}

Department of Applied Physics, Nanjing University of Science and Technology, Nanjing, Jiangsu 210094, China.

*Electronic mail: jysu@iccas.ac.cn; jysu@njust.edu.cn

\section{Supporting Information}

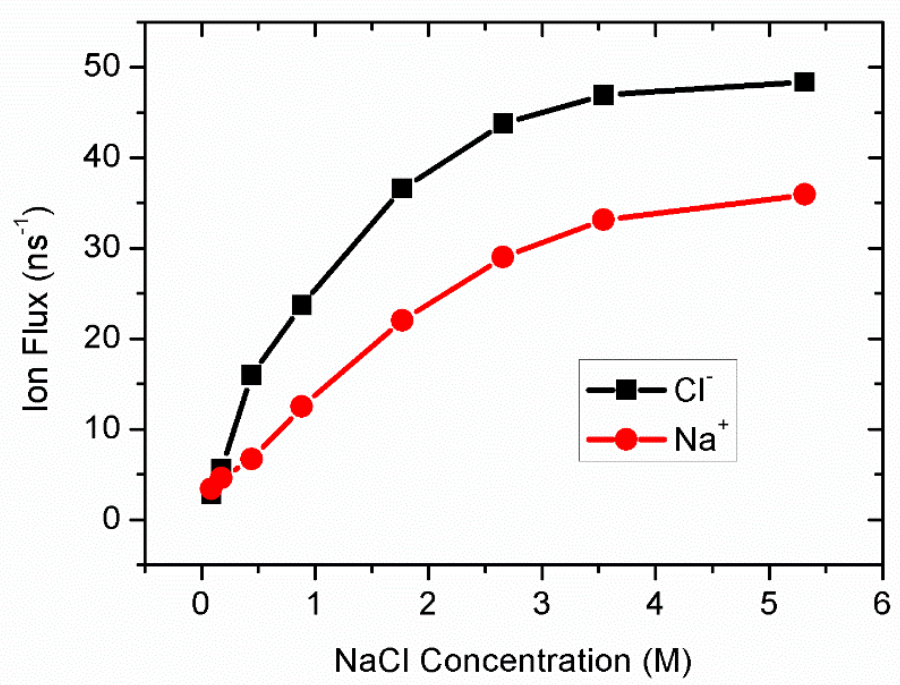

Figure $\mathrm{S} 1$. Average ion flux as a function of $\mathrm{NaCl}$ concentration for the $\mathrm{CNT}(15,15)$ with length of $2.56 \mathrm{~nm}$ and diameter of $2.02 \mathrm{~nm}$. 